\title{
A study of fluid provision and consumption in a rehabilitation hospital in Scotland, UK
}

\author{
L. Williams, J. Jones, Him Davidson and E. Bannerman \\ Queen Margaret University, Queen Margaret University Drive, Musselburgh, East Lothian, EH21 6UU, UK
}

\begin{abstract}
Adequate hydration is essential to help prevent problems such as constipation, pressure sores and confusion ${ }^{(1)}$. Potential risk factors in older adults include, reduced thirst mechanisms, increased skin losses, increased urine production and reduced intakes due to fear of incontinence ${ }^{(2)}$. Dehydration may prolong illness and increase length of hospital stay ${ }^{(3)}$. Current standards on food and fluid provision state a minimum provision of $1500 \mathrm{ml}$ of fluid/day, constant access to fresh drinking water and regular provision of assorted beverages at the correct temperature with assistance to drink if required ${ }^{(4,5)}$. The aim of this study was to evaluate fluid provision and consumption in patients (>65 years) in a long stay hospital.

Daily fluid provision and consumption in 58 patients $(12 \mathrm{~m}, 46 \mathrm{f})$ on three orthopaedic rehabilitation wards were assessed. Fluid provision was measured by determining the average fluid content of a jug and a cup on each ward. Each new jug of water provided was recorded along with acceptance of each hot or cold drink over the course of the day. Intake was determined by measuring the leftover water in each jug when the jugs were refreshed, and by measuring any leftover liquid in patients' cups. Observations were carried out on each ward concerning presentation and encouragement of fluid consumption. Estimated intakes were compared against standards for fluid provision in hospitals ${ }^{(5)}$ using a one-sample t-test.

Patients were provided with covered jugs of drinking water at their bedside, however the recommendation of a jug change at least $3 \times / \mathrm{d}^{(5)}$ was not met $(27 / 58 \times 1$ change/d, $31 / 58 \times 2 /$ day, $0 / 58 \times 3 /$ day $)$. Hot/cold beverages were offered at five to six opportunities throughout the day (depending on the ward). Fifty-six out of 58 patients monitored were provided with more than the recommended minimum $1500 \mathrm{ml} /$ day (see Table), however, mean fluid intake was significantly lower than recommended $(\mathrm{mean}=1302(\mathrm{SEM}=60) \mathrm{ml}$, $\mathrm{p}=0.002$ ) with 35 out of 58 patients consuming $<1500 \mathrm{ml} / \mathrm{d}$ and $14 / 58$ patients consuming $<1000 \mathrm{ml} / \mathrm{d}$.
\end{abstract}

\begin{tabular}{|c|c|c|c|}
\hline Fluid & Mean Fluid (ml) & Standard Error Mean $(\mathrm{ml})$ & $\begin{array}{l}\text { Standard Deviation (ml) } \\
\text { (m) }\end{array}$ \\
\hline \multicolumn{4}{|l|}{ Provision } \\
\hline total & $2379 *$ & 82 & 623 \\
\hline hot/cold drink & 956 & 44 & 338 \\
\hline jugs & 1398 & 54 & 410 \\
\hline \multicolumn{4}{|l|}{ Consumption } \\
\hline total & 1302 & 60 & 455 \\
\hline hot/cold drink & $770^{\#}$ & 46 & 350 \\
\hline jugs & 513 & 36 & 271 \\
\hline
\end{tabular}

While $77 \%$ of hot/cold beverages from the trolley were consumed, only $41 \%$ of the water provided was drunk. Provision of fluid as hot/ cold drinks was less than that from jugs $(\mathrm{p}=0.002)$ however consumption of hot/cold drinks was greater $(\mathrm{p}<0.001)$.

Provision of fluid to patients in orthopaedic rehabilitation wards meets the minimum standard of 1500 mls/d, however two-thirds of patients were consuming less than this. This suggests that current strategies to promote intakes are not meeting patients needs. Greater emphasis needs to be placed on putting mechanisms in place to ensure that patients are encouraged to drink, in order to prevent dehydration and its associated complications. Consumption is higher when drinks are given directly to patients rather than from a jug, suggesting a potential strategy for improving intakes is to increase the frequency of the trolley service. Further research would be useful to determine whether this is viable.

1. Water UK (2007) Hydration Toolkit for Hospitals and Healthcare.

2. Hodgkinson B, Evans D \& Wood J (2003) Int J Nurs Prac 9(S):19-28.

3. Mukand JA, Cai C, Zielinski A, Danish M \& Berman J (2003) Arch Phys Med \& Rehab 84(1):58-61.

4. NHS QIS (2003) Clinical Standards for food fluid and nutritional care.

5. Scottish Government (2008) Food in hospitals: catering and nutrition specification for food and fluid provision and nutritional care in hospitals in Scotland. 